casters also present valuable data and opinions as to weather and temperature forecasts in their respective districts.

The subject of high winds is efficiently treated by Forecaster E. H. Bowie, who indicates the various types of pressure from which they occur. While pressure gradients induce high winds of definite relative force, yet exceptions to the rule are noted. Hurricanes, northers and blizzards receive due consideration. He mentions the intensity of action, caused by twelve different types of lows. Special supplementary treatment of the storm winds of the Atlantic and Gulf coasts is presented by Professor H. C. Frankenfield, and similar data for the North Pacific coast by Forecaster Bealls, for the South Pacific coast by Forecaster Willson, and for the Great Lakes by Professor Cox.

Professor H. C. Frankenfield discusses the forecasting of snow, of sleet and ice storms, dwelling especially on their seasonal and geographic distribution. He indicates seven distinct conditions precedent to sleet and ice storms, and five necessary conditions preceding fog formation. Similar treatment of thunderstorms comes from Professor Henry.

Forecaster Bowie in discussing long-range weather forecasts considers seasonal forecasts as improbable even in the near future. $\mathrm{He}$ indicates, however, sixteen types of pressure conditions in various regions of the northern hemisphere which enable meteorologists to forecast conditions, elsewhere consequent, from two days to two weeks in advance.

The bibliography and index are unsatisfactory, and most annoying to any student. There are about a score of publications referred to in the text which do not appear in the bibliography, while titles of small import are given place. This is a small matter, but it mars the publication.

As a whole, while these memoirs will be indispensable to every forecaster and experienced meteorologist, as far as the public is concerned they will be valuable only to advanced students of the science. They are quite beyond the scope indicated by Chief Marvin as a text-book or manual suitable for the guid- ance and instruction of beginners. It is to be hoped that in due time there will appear a series of local manuals-not more than 24 pages in length-wherein should be presented such simple rules as would enable business men to still further utilize the daily weather map. The writer had a similar intent when he incorporated in American Weather twelve rules for general use in weather forecasting, which the board of professors has generously recognized in their preface. Doubtless a hundred similar rules-simpler and better-could be deduced by the experienced professors who have prepared these memoirs, whose value to students is recognized as of the highest order.

\section{A. W. Greely}

WASHINGTON, D. C.

\section{SPECIAL ARTICLES}

THE RESULTS OF EXTIRPATION OF THE ANTERIOR LOBE OF THE HYPOPHYSIS AND OF THE THYROID OF RANA PIPIENS LARVE

THE writer has long been impressed with the desirability of testing the effects of extirpation of the glands of internal secretion at the very beginning of their development in order to determine the part that they play in the development and differentiation of the embryo. Of all the vertebrates the anurans seemed to offer the greatest opportunities for such work. Adler ('14) ${ }^{1}$ performed experiments of this kind, but the operation was carried out at a late stage and consequently did not entirely exciude the early influence of the gland. Early in the spring of 1915 the writer removed the anlage of the anterior lobe of the hypophysis at the time of closure of the medullary folds by removing the surface ectoderm from which it would shortly afterwards develop. This attempt resulted in a large degree of mortality and was abandoned. This spring the operation was successfully accomplished by making a transverse frontal cut extending back the entire length of the fore brain and parallel to it a sufficient distance below to just expose the ventral surface of the hy-

1 Adler, L., “Metamorphosestudien an Betrachierlarven. I. Extirpation endokriner Drüsen. A. Extirpation der Hypophyse." Arch. f. Entwickelungsmech. d. Organ., Bd. 39, 1914. 
pophysis ingrowth. When this is performed at the stage of from 3.5-4 mm. total body length the hypophysis anlage can be readily seen and removed. The wound heals in from 20 to 30 minutes and the tadpoles quickly recover. In the course of these experiments the anlage was successfully removed from 430 tadpoles.

This phase of my work was duplicated by Dr. P. E. Smith, ${ }^{2}$ who published a preliminary account of his work in the August 25, 1916, number of ScIENCE. During the month of July prior to this time I had the pleasure of discussing my work with Dr. Smith at Berkeley. Previous to this time I had no knowledge of his work nor of his plans and he assures me that he was equally ignorant of my work. We both presented papers upon our experiments at the meeting of the Western Society of Naturalists at San Diego, August 9 to 12. On the 7th of June, before starting west, I demonstrated specimens and explained my results to a number of scientists, including Professor Frank R. Lillie, Dr. Emil Goetsch, Dr. Chas. H. Swift and a number of others whom I met in Chicago at that time. It is thus clear that these experiments were independently conceived by Dr. Smith and myself and that we worked contemporaneously upon them each without knowledge of the other's work until July, 1916, two months after the experiments had been performed. It was impossible to give an earlier report upon this work because the experiments upon thyroid removal required a long period of time to establish definite results.

Our results are in accord in showing that the removal of this gland has an early effect in producing a great contraction of the superficial pigment cells. The results in my specimens were very striking. I found that my tadpoles assumed a uniform creamy silver color. This change was evident on the seventh to eighth day after the operation. Our work is further in accord in that we both observed a retardation in growth very marked in my material and a striking retardation in the development of limbs. The buds appeared but

2 Smith, P. E., "Experimental Ablation of the Hypophysis in the Frog Embryo," Scrence, August 25, 1916, p. 280. remained very small. One specimen kept alive until August 30 had only reached a length of $30 \mathrm{~mm}$. and the limb buds were still extremely small after the controls had all fully metamorphosed into frogs. Through all this time it maintained its silvery color.

Dr. Smith found that there was no more mortality among his operated tadpoles than among the controls. This is quite contrary to my experience; but is no doubt explainable upon the grounds that he had a more favorable water supply than ours. In my experiments. upon removal of the hypophysis there was a very heavy mortality. I am convinced that this must be explained upon the ground that the presence of the hypophysis anlage is necessary for the proper adjustment of the tadpoles to these injurious influences. It might be mentioned at the outset that in roughly one third of the operated tadpoles the upper part of the mouth was defective. This was due to the removal or disturbance of its anlage in the operation. These tadpoles were of course doomed to die, but this can not account for the fact that in one experiment in which 30 were operated only 4 remained alive at the end of 33 days.

In another experiment the case was made still more clear. Of 100 operated tadpoles only 7 remained alive at the end of 32 days - of these there had been failure to remove the hypophysis in one case and in another there had probably been partial failure. A control set was reared in which the cut was made as though for removal of the hypophysis, but the gland was left intact. Of the 28 thus treated 14 were alive at the end of 42 days. At this time they were in a very flourishing condition, although the operation caused a temporary retardation of growth.

In other sets of experiments there were usually one or two tadpoles that failed to show the characteristic color change. These were invariably hardy. Upon sectioning them the hypophysis was found intact.

Operated tadpoles and control lots were kept side by side in the same or neighboring aquaria and the operated ones invariably showed heavy mortality while the control tadpoles were healthy. This mortality did not appear until 
at least a week after the operation, long after complete recovery, and it was not evident in certain cultures so long as they were kept in well water, appearing only after they were placed in our city water.

The interesting thing is that other tadpoles that had undergone a more severe operation in the removal of the thyroid gland showed no appreciable mortality until after the lapse of a month, when they had grown so large as to crowd the aquaria. These were kept in conditions identical with those under which the tadpoles deprived of the hypophysis showed such heavy mortality.

I propose next spring to determine if possible whether this lack of resistance is of a general character or whether the absence of the hypophysis causes a heightened susceptibility to specific injurious substances or conditions.

These experiments upon removal of the hypophysis represent only one phase of my work; similar methods were applied to the extirpation of the thyroid anlage. This was removed at a slightly later stage $6-6.5 \mathrm{~mm}$. total length shortly after it appeared. In this case a transverse cut was made between the heart and the thyroid anlage and the latter was readily removed. In some instances a small portion of it may have been left behind, but in the main the operation proved successful as demonstrated in sections of operated tadpoles. Recovery from the operation was quite as rapid and complete as in the case of hypophysis extirpation. This operation was successfully performed upon 336 tadpoles.

As indicated above, for a long time after the operation the tadpoles showed no ill effects from the absence of the thyroid gland as regards either size or vitality. In fact they appeared in every way normal up to the time when the hind limbs began to form. When they began to die as a result of overcrowding and other unfavorable conditions that became marked at about 6 weeks after the operation, there was an even greater mortality among the controls.

The metamorphosis of the controls began about the middle of July and continued to August 13, when the last control tadpole meta- morphosed. Five of the operated tadpoles metamorphosed at about the same time as the controls. One metamorphosed much laterSeptember 20.

At the present date, Octóber 1, twelve operated tadpoles ranging in length from $85 \mathrm{~mm}$. to $123 \mathrm{~mm}$. are living and show no tendencies toward metamorphosis. The hind-limb rudiments are rather uniformly about $4 \mathrm{~mm}$. in length. The knee is evident and the toe points distinguishable. The larval characters as a whole are maintained. The intestine, the mouth, eyes, etc., are all larval in character, although a peculiar modification in the form of the head is noted in that the portion in front of the eyes is lengthened, broadened and flattened dorsoventrally. It is thus clear that the removal of the thyroid gland has caused these tadpoles to remain in a larval condition for a month and a half after the controls have completed metamorphosis. Section of 7 operated tadpoles at various stages from 9 to $24 \mathrm{~mm}$. showed no vestiges of the thyroid gland. A careful study of the operated animals that have undergone metamorphosis is being carried on to determine whether small portions of the gland have remained after the operation or whether there may not have been new formation of thyroid tissue. Upon sectioning one of these a single well-developed thyroid gland was found on one side. This clearly shows that we were here dealing with a case of imperfect removal.

The results of this experiment establish a corollary to the experiments by which Gudernatsch and others have shown that thyroid feeding-hyperthyroidism-greatly accelerates metamorphosis. Conversely, in the absence of the thyroid gland metamorphosis is at least greatly retarded. How long this may continue remains to be seen.

A careful study of the material is being made to observe the effects of the removal of these glands of internal secretion upon the body as a whole and upon the various organs. The results should be especially interesting because we are dealing with material in which the earliest anlagen of these glands have been removed. Bennet M. Allen 
P. S. As this goes to press, November 17, nine of the thyroidless tadpoles are still alive and have increased in size. One has been fed thyroid preparations for 25 days but in very small amounts and at long intervals for fear of fatal results. The hind legs have reached a length of $9.5 \mathrm{~mm}$. and the fore legs are evident beneath the skin. The tail has become greatly shortened and the head is assuming the character of a frog's head. The legs of all the other tadpoles have remained stationary in development at a length of $4 \mathrm{~mm}$. and the tadpoles as a whole show no further signs of metamorphosis. Another tadpole of $29 \mathrm{~mm}$. heavily fed with thyroid, died after 4 days. When compared with a thyroidless tadpole of practically equal body length it was found the intestine of the thyroid fed tadpole had been reduced to a length of $143 \mathrm{~mm}$. as compared with $237 \mathrm{~mm}$., the length of the intestine of the thyroidless tadpole that had not been fed thyroid.

B. M. A.

\section{MICROTECHNICAL METHODS FOR STUDYING CERTAIN PLANT-SUCKING INSECTS IN SITU}

A PROBLEM on which the writer has been working for the past year, viz., determining the relation of certain sucking insects to their host plants, has necessitated the development or adaptation of several points of microtechnique which may be of use to other investigators along similar lines. Sectioning insect and plant tissue together has not been attempted often, as the usual methods suitable for one are out of question for the other. It is also necessary to cut quite hard tissues and to employ stains for chitin which also will not dissolve the middle lamellæ separating the plant cell-walls.

The material for study must be fresh. Usually most satisfactory results are obtained if the bottles of killing fluid are taken into the field, the parts of plants bearing the insects cut off with a sharp knife, and immediately immersed. Aphididæ and others of the more active forms must be removed with the part of the plant on which they are feeding and killed before they have time to pull out the proboscis, otherwise their natural positions in feeding can not be studied. For the gelatine method of embedding, which the writer has used quite extensively, pieces of pine needles, each bearing a coccid at one end, are tied in bundles of ten to twenty, making it possible to get sections of many needles at once; with the use of a killing and fixing agent which penetrates rapidly and easily no difficulty from improper fixing of parts of these bundles is experienced.

Of the killing solutions a variety was tried, Jeffry's ${ }^{1}$ proving in most cases the most satisfactory, as the picric acid in it stains chitin. Also it softens hard plant tissues so that it is possible to cut paraffin sections of leaves as hard as Citrus without further softening. It may be used hot for twenty minutes or cold for several hours. Care must be taken to wash thoroughly in alcohol or iodin alcohol (30 per cent. alcohol which has been turned to a light wine color by the addition of iodin), otherwise crystals of mecuric bichlorid will remain. Carnoy's fluid ${ }^{2}$ also proves successful, particularly with active insects having much secretion of wax, e. g., the aphid Chermes, which with less quickly penetrating solutions encloses a drop of air, thus enabling the insect to free its beak before death. Its hardening properties are overcome by thorough washing in absolute alcohol, followed by 95 per cent., 85 per cent., 70 per cent., 50 per cent., 30 per cent. strengths, and then softening in Jeffry's solution.

The gelatine method for embedding ${ }^{3}$ has been found by the writer very successful for many hard tissues. It deserves extended trial with plant tissues usually considered too hard for sectioning. It is a short method: the material does not require dehydration before its use, therefore hard tissues are not rendered harder than they naturally are. Further, the

1 Corrosive sublimate, saturated solution in 30 per cent. alcohol, 3 parts. Picric acid, saturated solution in 30 per cent. alcohol, 1 part.

2 Absolute alcohol 6 parts, chloroform 3 parts, glacial acetic acid 1 part.

3 Land, W. J. G., "Microtechnical Methods," Bot. Gaz., Vol. 59, May, 1915, p. 400. Chamberlain, C. J., "Methods in Plant Histology,"' 3d revised edition, p. 128. 